\title{
SUSTENTABILIDADE URBANA E INDICADORES DE ÁREA VERDE NO MUNICÍPIO DE SÃO PAULO
}

\section{URBAN SUSTAINABILITY AND GREEN AREAS INDICATORS IN THE CITY OF SÃO PAULO}

\author{
Juliana Rodrigues Maróstica ${ }^{1}$ \\ Tatiana Tucunduva Philippi Cortese ${ }^{2}$ \\ Giuliano Maselli Locosselli ${ }^{3}$ \\ Cláudia Terezinha Kniess ${ }^{4}$
}

\begin{abstract}
Resumo
O presente estudo avalia o papel dos índices de áreas verdes e sua contribuição para a sustentabilidade urbana e redução da desigualdade ambiental, tendo como estudo de caso o município de São Paulo que possui uso e ocupação do solo heterogêneo e complexo. A pesquisa realizada tem caráter exploratório com abordagem qualitativa, e como resultado, verificou-se que não há um consenso na literatura sobre um valor ideal de índice de vegetação nas cidades, devido às diferentes escalas de análise dos estudos. O valor de IAVT (Índice de Áreas Verdes Totais) calculado foi de $16,70 \mathrm{~m}^{2}$ de área verde/habitante, acima do valor ideal de área verde atribuído à Organização Mundial da Saúde (OMS) de $12 \mathrm{~m}^{2}$. Porém, apenas 30\% das 32 subprefeituras do munícipio possuem realmente um índice superior ao recomendado, sendo que parte dessas áreas são florestadas. Portanto, o IAVT deve ser utilizado com cautela no desenvolvimento de políticas e ações que visam a redução da desigualdade ambiental visto que ele apresenta limitações, por não contemplar a arborização urbana, mas principalmente por não ponderar pela parcela da ocupação que pode ser mais, ou menos, urbana. O índice atribuído à OMS pode ser aplicado pois tornam as cidades comparáveis entre si, entretanto, não é adequado para políticas públicas locais por não representar precisamente a exposição da população às áreas verdes. Ainda, o IAVT pode ser adotado como parâmetro de tomada de decisão para a ampliação das áreas verdes na cidade, tais como a implantação de parques, buscando maior equidade ambiental.
\end{abstract}

\footnotetext{
${ }^{1}$ Mestre em Cidades Inteligentes e Sustentáveis (UNINOVE). Coordenadora de Projetos e Obras na Secretaria Municipal do Verde e do Meio Ambiente, São Paulo - SP, Brasil. E-mail: rodrigues.marostica@gmail.com

${ }^{2}$ Doutora em Saúde Pública pela Universidade de São Paulo. Professora da Universidade Nove de Julho, São Paulo - SP, Brasil. E-mail: taticortese@gmail.com

${ }^{3}$ Doutor em Botânica pelo Instituto de Biociências-USP. Jovem Pesquisador do Instituto de Botânica, São Paulo - SP, Brasil. E-mail: locosselli@yahoo.com.br

${ }^{4}$ Doutora em Ciência e Engenharia de Materiais pela Universidade Federal de Santa Catarina. Professora da Universidade de Taubaté, Universidade Federal de São Paulo e Universidade São Judas, São Paulo - SP, Brasil. E-mail: kniesscl@gmail.com
} 
Palavras-chaves: área verde, cobertura vegetal, indicadores, mudanças climáticas, sustentabilidade urbana.

\begin{abstract}
The present study evaluates the role of green area index and their contribution to urban sustainability and reduction of environmental inequality, taking as a case study the municipality of São Paulo, which has heterogeneous, and complex land use and occupation. The research carried out has an exploratory character with a qualitative approach, and as a result, it was found that there is no consensus in the literature on an ideal value of vegetation index in cities, due to the different scales of analysis of the studies. The value of IAVT (Total Green Area Index) calculated was 16.70 $\mathrm{m}^{2}$ of green area / inhabitant, above the ideal value of green area attributed to the World Health Organization (WHO) of $12 \mathrm{~m}^{2}$. However, only $30 \%$ of the 32 administrative regions (subprefectures) of the municipality actually have a higher index than recommended, with part of these areas being forested. Therefore, the IAVT should be used with caution in the development of policies and actions aimed at reducing environmental inequality since it has limitations, since it does not include urban afforestation, but mainly because it does not consider the share of occupation that may be more, or less, urban. The index attributed to WHO can be applied because they make cities comparable to each other, however, it is not suitable for local public policies because it does not accurately represent the population's exposure to green areas. Still, IAVT can be adopted as a decision-making parameter for the expansion of green areas in the city, such as the implementation of parks, seeking greater environmental equity.
\end{abstract}

Keywords: green area, vegetation cover, indicators, climate change, urban sustainability.

\title{
Introdução
}

A impermeabilização e compactação do solo e a intensa supressão da vegetação são alguns dos fatores resultantes da ocupação inadequada do território urbano. Estas mudanças no uso e ocupação do solo acompanham as transformações que culminaram no estilo de vida contemporâneo. Tais transformações decorrem da demanda por serviços básicos e da infraestrutura mínima para a população, incluindo: habitação adequada, fornecimento de água potável, coleta e tratamento de esgoto, energia elétrica, sistema de transporte, entre outros (CORTESE e NATALINI, 2014). A magnitude destas transformações depende da relação direta entre necessidade de serviços básicos e número de habitantes. Esta disposição se reflete na população urbana que, atualmente, é representada por cerca de $54 \%$ da população mundial, a qual estima-se que alcançará cerca de $66 \%$ até o ano de 2050 (Centro Regional de Informações das Nações Unidas [UNIRIC], 2018). Assim, a demanda crescente por mudanças no uso e ocupação do solo impõe pressão cada vez maior sobre a qualidade de vida no ambiente urbano.

A expansão urbana que legitimamente busca suprir as necessidades da população, quando desordenada, gera uma série de consequências ambientais negativas. Estas incluem um aumento da vulnerabilidade do ambiente urbano às mudanças climáticas, devido a características intrínsecas das cidades como a formação de ilhas de calor. Além de afetar o conforto térmico localmente, as ilhas de calor promovem atividades convectivas na cidade potencializando o aumento da frequência e intensidade de eventos extremos de precipitação, já esperados pelas alterações no regime climático global (MARENGO et al., 2020). A combinação destas mudanças nos regimes de chuvas com a alta demanda por recursos hídricos e com impermeabilização do solo, levam a consequências rigorosas na cidade, da escassez de água às enchentes. Estes são considerados os dois piores desastres naturais em cidades, afetando a infraestrutura, atividades econômicas e a saúde da população (MUIS et al., 2015; GU et al., 2015; LARSEN et al., 2016). Referidas variações nos regimes de temperatura e precipitação somam-se ao impacto da expansão urbana sobre a biodiversidade local que, em conjunto, podem resultar no aumento da probabilidade da proliferação de zoonoses, como dengue ou malária (FRANKE e HACKBART, 2008). 
O enfrentamento destes desafios urbanos, tais como: a mobilidade urbana, qualidade do ar, saúde e segurança, as mudanças climáticas, entre outros, são barreiras a serem superadas para a busca do desenvolvimento regional, e demandam ações coletivas (SILVA et al., 2019) que promovam a integração entre o ambiente, a economia, a cultura e a sociedade, como por exemplo a Agenda 21 (CARVALHO, 2014). Dentro desse contexto, portanto, as áreas verdes possuem papel chave para busca do desenvolvimento sustentável e regional, visto que atuam na promoção de um ambiente equilibrado, ao mesmo tempo em que promovem interações culturais e sociais (ACSELRAD, 1999).

As áreas verdes são apontadas pela literatura e políticas públicas como importantes instrumentos na busca da sustentabilidade urbana e da mitigação das mudanças climáticas (THE NATURE CONSERVANCY, 2019), com o objetivo de promover a melhoria da qualidade de vida. Estes benefícios vão ao encontro do proposto pelo artigo 225 da Constituição Federal de 1988, que preconiza o direito a um ambiente equilibrado que promova a manutenção da qualidade de vida das pessoas. Além de benefícios à cidade, como estéticos e sociais, vincula melhorias na qualidade de vida, saúde mental e física (BENAYAS, NEWTON, DIAZ e BULLOCK, 2009; ASGARZADEH et al., 2012).

Em um cenário local, no município de São Paulo, cuja extensão territorial é de $1.521,110 \mathrm{~km}^{2}$, a realidade é muito mais complexa (CARVALHO e DAMACENA, 2012), visto que a sua população está estimada em 12.106.920 pessoas e 98\% dela vive no ambiente considerado urbano (Instituto Brasileiro de Geografia e Estatística [IBGE], 2018). Essa população está exposta a um gradiente amplo de condições ambientais que apenas ressaltam a desigualdade observada na região (LOCOSSELLI et al., 2020) e, em grande parte, a desigualdade está associada à distribuição heterogênea das áreas verdes dentro do município (SILVA et al., 2019). Exemplo desse heterogeneidade do munícipio de São Paulo são as subprefeituras localizadas predominantemente na Região Sul, que concentram grande parte das áreas verdes em extensão relativa e se beneficiam de níveis de poluição até 50\% menores (MOREIRA et al., 2018) e temperaturas superficiais até 25\% menores (FERREIRA e DUARTE, 2019). A concentração das áreas verdes resulta na redução de alguns problemas de saúde na população diretamente associada, como a redução significativa nos casos de hipertensão (MOREIRA et al., 2020).

Esses trabalhos apresentados por MOREIRA et al. $(2018,2020)$ e FERREIRA e DUARTE (2019), conduzidos no próprio município de São Paulo, demonstram a magnitude dos benefícios promovidos pelas áreas verdes à população associada e que referidos benefícios são diretamente proporcionais à extensão relativa destas dentro da malha urbana. Sob o foco na utilização das áreas verdes como instrumentos de importância ecossistêmica para as cidades, demonstra-se o papel das áreas verdes e sua contribuição para a sustentabilidade urbana e para o desenvolvimento regional, por meio da análise dos indicadores de distribuição da área verde da cidade de São Paulo (SP). O indicador analisado será o IAVT (Índice de Áreas Verdes Totais) do munícipio São Paulo, em seus valores totais, por região e por subprefeitura.

\section{Referencial Teórico}

O presente tópico tem como objetivo fundamentar a base teórica que suportará as futuras discussões, análise de dados e diagnósticos a serem desenvolvidos durante a pesquisa. Para tal, dividiu-se em três pilares teóricos, sendo eles: desenvolvimento regional, sustentabilidade urbana e instrumentos de gestão.

\section{Sustentabilidade Urbana}

A ideia de sustentabilidade urbana surge da combinação do espaço urbano ao conceito de sustentabilidade, originado pelas rearticulações políticas, como a Agenda 21, que busca um mundo mais justo socialmente, a conservação ambiental e o crescimento econômico e a Agenda 2030 da Organização das Nações Unidas [ONU], apresentada como um plano de desenvolvimento global com ações de longo prazo e 17 Objetivos de Desenvolvimento Sustentável estabelecidos. Uma vez que referidos documentos englobam aspectos culturais, sociais, econômicos, políticos e ambientais, dependem de políticas públicas interdisciplinares, interdependentes e sistêmicas para produzir efeitos concretos (SOTTO et al., 2019).

Essa urbanização intensa, aliada às consequências das mudanças climáticas, é um desafio para as cidades em todos os pormenores. Medidas de mitigação e adaptação são estabelecidas por meio dos documentos apresentados pelos governos federais intitulados Contribuição Nacionalmente 
Determinada e planos de ação estadual e municipal tornam-se instrumentos necessários de gestão. Dentro desse contexto, as áreas verdes possuem um papel chave para busca do desenvolvimento urbano, visto que atuam na promoção de um ambiente equilibrado, ao mesmo tempo em que promovem interações culturais e sociais (ACSELRAD, 1999).

Os benefícios das áreas verdes se estendem tanto a fatores estéticos, espirituais e de recreação, quanto à questões de saúde pública, sendo ela física e mental, além de aspectos positivos ligados ao meio ambiente (THE NATURE CONSERVANCY, 2019). Porém, para alcançar referidos benefícios, é imprescindível planejar de maneira adequada o uso e ocupação do solo, o crescimento populacional, as condições ambientais, a distribuição territorial das áreas de lazer. Cada município tem características próprias e as áreas verdes têm funções ecológica, educativa, estética, psicológica e social que deverão estar inseridas no planejamento urbano, seguindo o tipo de uso a que se destinam.

\section{Desenvolvimento regional}

O planejamento ambiental urbano, com promoção da sustentabilidade, integra temas globais da agenda ambiental mundial como mudanças climáticas e soluções baseadas na natureza até temas ambientais de agendas de desenvolvimento regional. De acordo com o Ministério de Desenvolvimento Regional [MDR], o desenvolvimento regional deve ser depreendido de maneira multidimensional, isto é, com suas múltiplas escalas de intervenção, visando desenvolver o território com planos, programas e projetos que reconheçam as desigualdades em escalas múltiplas de intervenção Ele compreende medidas ou políticas que tem como objetivo "corrigir desequilíbrios regionais para garantir uma distribuição mais paritária da população e das atividades econômicas em todo o território" (MAILLAT, 1998).

O desenvolvimento regional é, portanto, um tema multidisciplinar (CARNIELLO e SANTOS, 2013) que deve ser entendido e observado em conjunto com os aspectos culturais e sociais, tais como a educação, saúde, qualidade de vida, empregabilidade (SILVA, KOVALESKI E PAGANI, 2019). Atualmente, a Política Nacional de Desenvolvimento Regional (PNDR) é preconizada pelo Decreto $\mathrm{n}^{\circ}$ 9.810, de 2019, contudo, de acordo com Cavalcante (2020) "a base legal dessas iniciativas é a própria Constituição Federal de 1988, que consagra a redução das desigualdades regionais como um dos objetivos fundamentais da República Federativa do Brasil". Portanto, para reduzir as desigualdades regionais, é necessário que os instrumentos de gestão estejam alinhados a esse objetivo.

\section{Instrumentos de Gestão para o desenvolvimento regional}

As políticas públicas são importantes instrumentos para a busca da mudança dos paradigmas atuais, tais como a mitigação dos efeitos das mudanças climáticas e o alcance da almejada sustentabilidade urbana e desenvolvimento regional, "pois alteram ou mantêm comportamentos de cidadãos ou organizações para obter um resultado comum desejável. Além disso, são aplicáveis a diversas questões e de modo abrangente, envolvendo cidadãos, empresas, comunidades e instituições" (JUSTI e RAUEN, 2020). A conservação das áreas verdes urbanas (MEIJER e BOLÍVAR, 2016) e o controle dos recursos ambientais associados à gestão social eficiente (DA SILVA, 2003) consistem em instrumentos chave dentro desta busca.

Dado que a gestão social depende de capacidades institucionais avançadas, governança democrática e gestão eficaz para enfrentar desafios (LEITE e AWAD, 2012), para tornar as políticas públicas instrumentos eficientes, destaca-se a importância de análises críticas sobre a legislação e regulamentação urbanística e ambiental em vigor, governança participativa e gestão eficiente para enfrentar desafios (MEIJER e BOLÍVAR, 2016) Nesse contexto, a governança e as políticas públicas como instrumentos de regulação possuem papel fundamental no desenvolvimento de uma cidade inteligente e sustentável (MEIJER e BOLÍVAR, 2016), conforme apresentam MACHADO; VILANI; CHAME (2012, p. 12) "a perda de qualidade ambiental e a redução do estoque de recursos naturais requerem um novo direcionamento na agenda de temas e problemas a serem discutidos e institucionalizados por meio da formulação e/ou do aprimoramento de políticas públicas”.

Portanto, é inevitável a que a elaboração de novas políticas eficientes e tomada de decisões sejam apoiadas em evidências científicas, sendo necessária a adoção de parâmetros e/ou indicadores. Indicadores são parâmetros quantitativos e qualitativos, obtidos por meio da associação de duas variáveis diferentes e/ou fatores para o estudo e busca da identificação e mensuração de um 
problema, bem como a identificação e escolha da estratégia de atuação e solução dos problemas (FREITAS, 2013). O Índice de Área Verde Total [IAVT] é um exemplo que tem como objetivo a "avaliação da distribuição das áreas verdes públicas na cidade, independentemente de sua função, ou seja, para uso de lazer e contemplação (parques urbanos e praças, com uso intensivo) ou para conservação de ecossistemas (uso restrito, para pesquisa)" (SVMA, 2013). Cumpre destacar que entende-se como áreas verdes todas as áreas verdes de domínio público, ou seja, praças, parques, canteiros, etc. Destaca-se que arborização viária e demais árvores isoladas são consideradas como cobertura vegetal.

Este estudo teve como objetivo avaliar o uso de índices de vegetação como instrumento de desenvolvimento regional, principalmente para a redução da desigualdade ambiental urbana. Assim, respondeu-se às seguintes perguntas: I) Há um consenso na literatura sobre um valor ideal de índice de vegetação nas cidades? II) A aplicação deste índice em diferentes escalas geográficas resulta em padrões semelhantes de exposição da população à extensão das áreas verdes? III) Estes índices podem ser utilizados de forma consistente para elaboração de políticas públicas de desenvolvimento regional com foco nas desigualdades ambientais? O município de São Paulo foi utilizado como estudo de caso por possuir uma gama de dados geoespaciais necessários para responder a estas perguntas.

\section{Metodologia}

A pesquisa realizada neste artigo tem caráter exploratório com abordagem qualitativa. $\mathrm{O}$ objetivo primário da exploração é, via de regra, desenvolver conceitos de forma mais clara e formular um problema de pesquisa mais bem delineado. A pesquisa exploratória estabelece critérios, métodos e técnicas para a elaboração de uma pesquisa e visa oferecer informações sobre o objeto desta e orientar a formulação de hipóteses (Cooper \& Schindler, 2011; Martins \& Theóphilo, 2009). É utilizada para realizar um estudo no qual o principal objetivo da pesquisa é familiarizar-se com o fenômeno que está sendo investigado, de modo que a pesquisa subsequente possa ser concebida com um maior nível de aprofundamento.

Já os estudos com abordagem qualitativa têm o propósito de saber "como e porque as coisas acontecem", ou seja, de possibilitar o entendimento dos diferentes significados atribuídos pelas pessoas às suas experiências, valendo-se de técnicas de pesquisas apropriadas para registrar os entendimentos, as motivações e as interpretações (Cooper \& Schindler, 2011; Collins \& e Hussey, 2005). A avalição qualitativa é caracterizada pela compreensão, descrição, interpretação de fatos e fenômenos (Martins \& Theóphilo, 2009).

A problemática de pesquisa deste artigo está relacionada ao cotidiano das grandes cidades, com a busca da resposta de como os indicadores de área verde interferem na sustentabilidade urbana e no desenvolvimento regional. Nesse caso, a pesquisa exploratória tem como objetivo analisar uma determinada variável, o IAVT, a fim de compreender sua inserção e relação com a sustentabilidade urbana.

O desenvolvimento da pesquisa foi delineado em duas etapas: (a) levantamento de dados secundários: indicadores reais e ideais de área verde do município de São Paulo e (b) análise dos dados levantados por meio de comparação e cálculo de indicadores com dados secundários e da elaboração e análise visual de mapas, conforme descrito a seguir.

$\mathrm{Na}$ primeira etapa ocorreu o levantamento dos dados necessários para o cálculo dos indicadores, sendo eles: o valor em metros quadrados das áreas verdes do munícipio de São Paulo, bem como o número de habitantes. Os dados das áreas verdes por subprefeitura foram obtidos por meio de pesquisa documental junto à Secretaria do Verde e do Meio Ambiente - SVMA e podem ser solicitados diretamente pelo Portal da Transparência em (https://www.prefeitura.sp.gov.br/cidade/secretarias/controladoria_geral/coordenadoria_de_promo cao_da_integridade/index.php? $\mathrm{p}=225079$, acessado em XX de XX de 2019) enquanto que os dados de número de habitantes foram obtidos diretamente pelos portais de internet da Prefeitura Municipal de São Paulo - PMSP e IBGE, e calculados com auxílio do software Excel (Microsoft). Ainda nesta primeira etapa, buscou-se por parâmetros ideais para a comparação com os indicadores calculados, não só por meio da pesquisa documental junto às políticas públicas e aos instrumentos de regulação indutora, mas também em pesquisa bibliográfica realizada em publicações de alto impacto, nacional e internacional. 
Utilizando-se os dados relativos ao ano de 2017, publicados em 2018 pela SVMA e o número de habitantes da PMSP e IBGE para cada uma das 32 Subprefeituras do município, calculou-se os IAVT, dividindo o total de áreas verdes em $\mathrm{m}^{2}$ pelo número de habitantes, para o munícipio de São Paulo. Estes serão avaliados em três escalas espaciais: o primeiro considera os limites do município em sua totalidade, o segundo calcula os índices por região (cinco setores) e o terceiro calcula os índices por subprefeitura (32 setores).

A segunda etapa é referente a análise de dados e envolveu a realização das comparações entre os indicadores numéricos levantados com os ideais. Estas análises se dividiram em três cenários: a) na totalidade do munícipio, b) por região (Zonas Leste, Oeste, Norte, Sul e Central) e c) por Subprefeituras (analisando cada uma das 32 subprefeituras do município). Referidas análises utilizaram como ferramenta o software Excel para a construção de tabelas e gráficos. Ainda, construiu-se mapas do município com o auxílio do software QGIS Team Developer , a fim de elucidar de forma gráfica o levantamento numérico encontrado, e facilitar a análise na escala do território.

Ainda, comparou-se os números encontrados com os instrumentos de gestão existentes, com o objetivo de verificar a coerência dos indicares encontrados com as decisões adotadas pelas políticas públicas para a ampliação das áreas verdes na cidade. Os valores de área verde $\left(\mathrm{m}^{2}\right)$ projetados são provenientes das informações do Programa de Metas de 2017-2020 referente aos parques implantados, para os anos de 2019 e previstos para 2020, conforme pesquisa documental e observação participante, tais informações podem ser buscadas por meio do Portal da Transparência, conforme já citado anteriormente.

\section{Resultados e Discussão}

Esta disparidade das informações obtidas a partir de um valor fixo de IAVT, como os 12m2 / hab., fica evidente quando se avalia a cobertura de áreas verdes na cidade de São Paulo. Dentro da escala do município, em sua totalidade, apresentou-se os valores resultantes de: IAVT $=16,70$ $\mathrm{m}^{2} /$ hab. (Área Verde $=194.138 .890 \mathrm{~m}^{2} \mathrm{e} \mathrm{n}^{\circ}$ de habitantes $=11.696 .088$, Tabela 2), valor esse que não apenas atende o valor recomendado pela OMS, como o supera em cerca de $40 \%$. Este valor ainda supera os $15 \mathrm{~m}^{2}$ / hab. recomendado pela SBAU (1996) e os índices reais calculados do município de Vinhedo (2,19 $\mathrm{m}^{2}$ por habitante) (HARDER, RIBEIRO E TAVARES, 2006).

A análise por região, de acordo com a segunda escala espacial, revelou uma heterogeneidade de valores muito distintos do índice calculado. Como exemplo, apenas as Regióes Norte e Sul atendem ao indicador considerado ideal pela OMS, enquanto as demais regiões apresentam o IAVT inferior em no mínimo 50\% a este indicador ideal (Tabela 2). Considerando a terceira escala espacial avaliada, ou seja, dentro dos domínios das subprefeituras, os resultados revelam uma desigualdade ainda mais evidente na distribuição das áreas verdes. Apenas 10 das 32 subprefeituras atendem aos indicadores ideais $\left(12 \mathrm{~m}^{2}\right)$, ou seja, apenas cerca de $30 \%$. A Erro! Fonte de referência não encontrada. apresenta os resultados desses indicadores por Subprefeitura do munícipio de São Paulo. O presente estudo utilizou dados de 2017 e apresentou resultados diferentes dos encontrados na pesquisa de BUCKERIDGE (2015), essas diferenças apontam que, atualmente, a maior concentração de áreas verdes está nas regiões Norte e Sul, e não mais na região central da cidade. Essa diferença de resultados deve-se em grande parte à implantação de parques municipais nessas áreas.

Tabela 1: Indicadores reais calculados por região do município de São Paulo

\begin{tabular}{ll}
\hline Região & $\begin{array}{l}\text { IAV } \\
\text { (dados de 2017) }\end{array}$ \\
\hline Zona Norte & $28,1^{*}$ \\
Zona Central & 2,5 \\
Zona Oeste & 5,4 \\
Zona Sul & $26,4^{*}$ \\
Zona Leste & 5,8 \\
\hline * acima do recomendado pela OMS
\end{tabular}


Figura 1: Mapa do Munícipio de São Paulo com a Indicação do IAVT

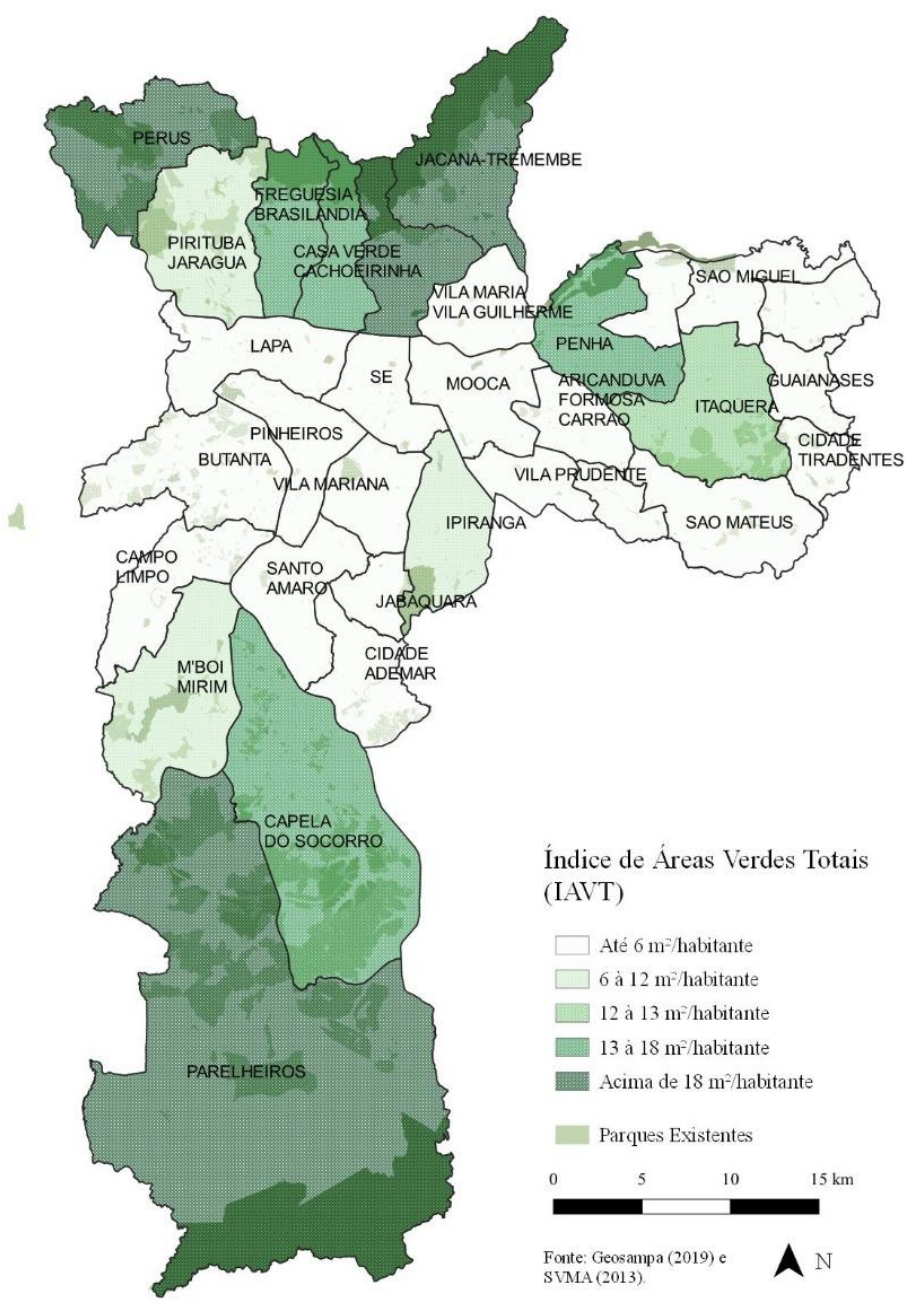

Fonte: Os autores.

Nota-se que que a região central apresenta valores menores do indicador, e que os maiores valores do indicador de área verde se encontram nas bordas da cidade. Este padrão espacial se justifica pela presença da Serra da Cantareira no norte da cidade, e de áreas extensas de Mata Atlântica no sul, que, em conjunto com outras áreas, compõem o cinturão verde de São Paulo. Além disso, o alto valor de IAVT dessas regiões pode ser também atribuído à baixa densidade populacional da região. Estas distinções na distribuição das áreas verdes são mais claras na Figura 2, que tem como objetivo demostrar a espacialização das áreas verdes no município em comparação com a verticalização e com a Densidade Demográfica. A Figura 2, apresentam maior concentração de áreas verdes em áreas menos verticalizadas e com menor densidade demográfica. Esses resultados ainda corroboram com Silva et. Al (2019), que aponta áreas altamente adensadas na cidade, na qual vivem populações de menor renda, muitas vezes nem sequer apresentam áreas verdes, e em contraste com regióes como no Sul do município, que possuem também populações de baixa renda cercadas de extensas áreas verde de proteção ambiental que não agregam maior qualidade de vida.

O Programa de Metas 2017-2020, instrumento de políticas públicas, foi repactuado pela Prefeitura Municipal de São Paulo em 2019, de forma a revisar os compromissos para o próximo biênio, 2019-2020, tendo como objetivo o enfrentamento dos principais problemas identificados na cidade. As iniciativas foram sistematizadas em três pilares, sendo eles: 1) cuidar da cidade, 2) proteger as pessoas e 3) inovar na gestão; e o programa é composto por 36 (trinta e seis) Objetivos 
Estratégicos e 71 (setenta e uma) metas. O Objetivo estratégico 30 e meta 30.4 preveem a Implantação de 10 novos parques na Cidades (Tabela 3).

Tabela 3: Previsão da implantação dos novos parques com o aumento de Áreas Verdes, conforme Programa de Metas 2017-2020 do Município de São Paulo.

\begin{tabular}{lllll}
\hline Ano & Zona & Subprefeitura & Parque & Área $\left.\mathbf{( m}^{\mathbf{2}}\right)$ \\
\hline 2019 & Oeste & Lapa & Jardim das Perdizes & 45.967 \\
\hline 2020 & Oeste & Butantã & Água Podre - Nascentes & 40.444 \\
\hline 2020 & Centro & Sé & Augusta & 24.613 \\
\hline 2020 & Sul & Cidade Ademar & Búfalos & 537.291 \\
\hline 2020 & Sul & Parelheiros & Ribeirão Colônia & 110.685 \\
\hline 2020 & Sul & Capela do Socorro & Linear Aristocratas & 36.884 \\
\hline 2020 & Sul & Campo Limpo & Paraisópolis & 68.150 \\
\hline 2020 & Sul & Santo Amaro & Alto da Boa Vista & 47.270 \\
\hline 2020 & Leste & Itaquera & Nair Belo & 246.863 \\
\hline 2020 & Leste & São Miguel & Primavera & 148.976 \\
\hline & & & Total & 1.307 .143 \\
\cline { 3 - 5 } & & & Total 2019 & 45.967 \\
\cline { 3 - 5 } & & & Total 2020 & 1.261 .176 \\
\cline { 3 - 5 }
\end{tabular}

Fonte: Os autores.

Percebe-se que mesmo o IAVT da região Sul da cidade apresentando o segundo melhor indicador com dados de 2017, dentre as regióes do município, e já atendendo os índices mínimos propostos pela OMS, ainda assim concentra cerca de $60 \%$ a área verde a ser ampliada até final de 2020, superando a Zona Norte e passando a ter o melhor índice do município. Enquanto que as Zonas Central, Leste e Oeste, que possuíam os menores indicadores e não atendiam aos parâmetros ideais, apesar do aumento, não foi significativo para a mudança desse cenário.

Tabela 4: IAVT calculado para 2020

\begin{tabular}{lll}
\hline Região & $\begin{array}{l}\text { IAV } \\
\text { (dados de 2017) }\end{array}$ & $\begin{array}{l}\text { IAV } \\
\text { (dados de 2020) }\end{array}$ \\
\hline Zona Norte & $28,1^{*}$ & $23,1^{*}$ \\
Zona Central & 2,5 & 2,7 \\
Zona Oeste & 5,4 & 5,8 \\
Zona Sul & $26,4^{*}$ & $28,2^{*}$ \\
Zona Leste & 5,8 & 7,4 \\
\hline
\end{tabular}

Os mapas a seguir apresentam a espacialidade da distribuição de áreas verdes em comparação com a verticalização e densidade populacional: 
Figura 2: Mapa do Munícipio de São Paulo indicando a verticalização e as áreas verdes e Mapa do Munícipio de São Paulo indicando a densidade demográfica e as áreas verdes

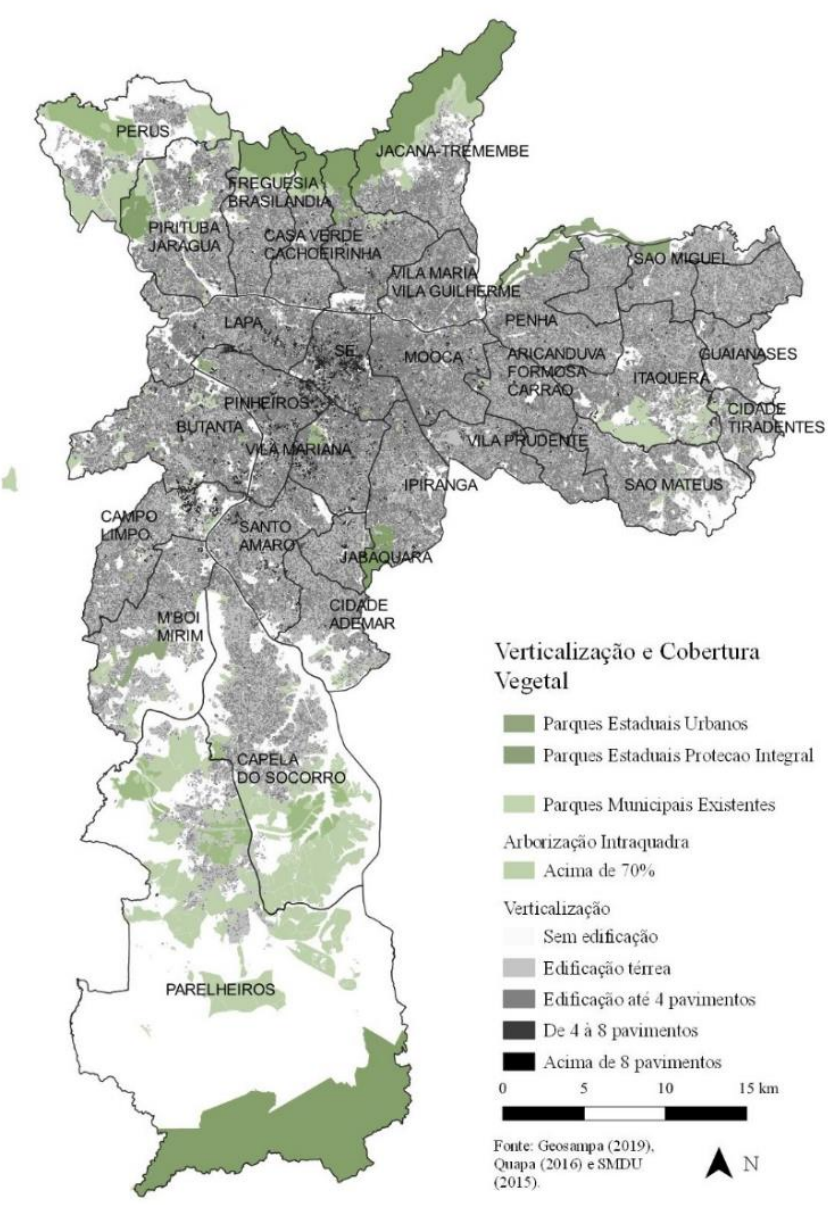

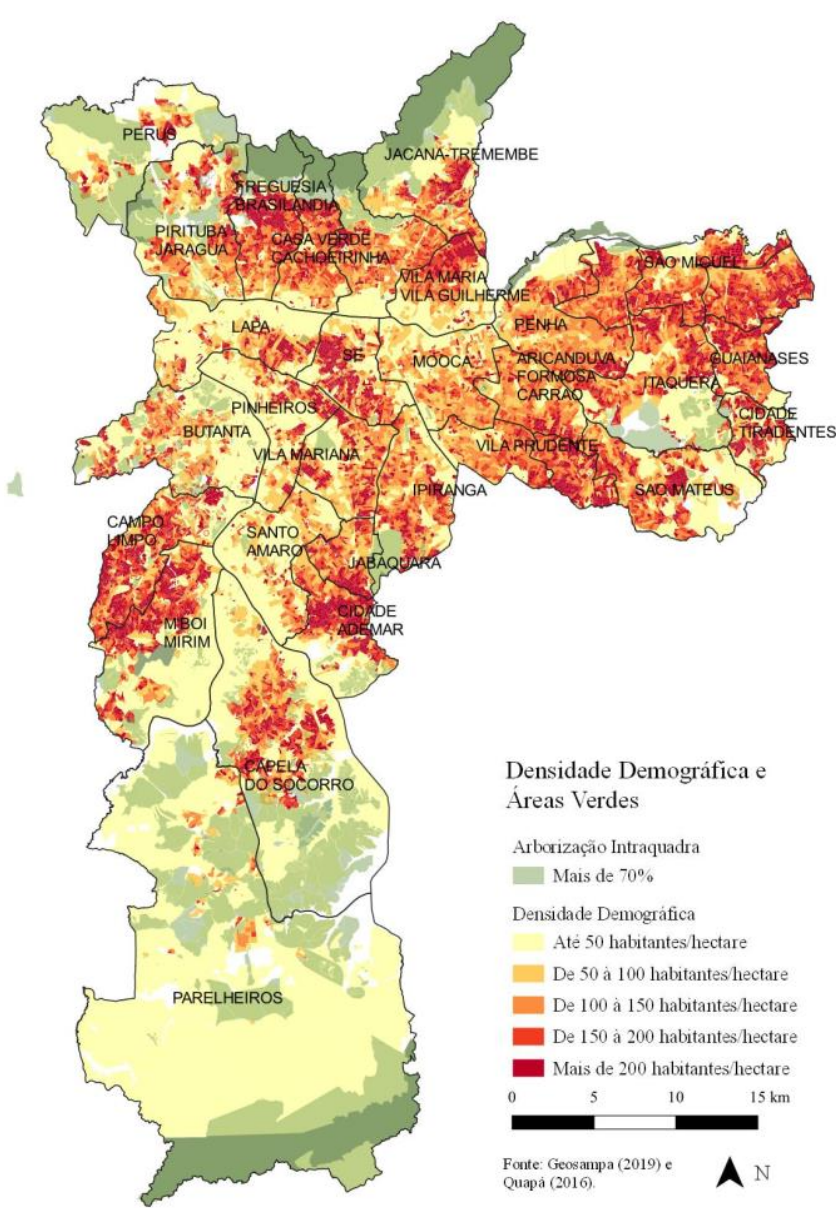

Fonte: Os autores.

\section{Conclusões}

O índice de áreas verdes, conhecido como Índice de Área Verde Total [IAVT], e cujo objetivo é a avaliação da distribuição das áreas verdes públicas na cidade, é um instrumento de gestão frequentemente utilizado pelas políticas públicas pautando as decisões de ampliação das áreas verdes na cidade, como é o caso de São Paulo, onde encontramos esses parâmetro sendo utilizado no Plano de Metas da Cidade de 2017-2020.

Porém, não há consenso na literatura quanto ao índice ideal que deve ser adotado. Esse índice varia consideravelmente, justificando a falta de consenso às diferentes escalas de análise dos estudos. $\mathrm{O}$ indicador de $12 \mathrm{~m}^{2}$ de área verde por habitante, atribuído à OMS, é amplamente difundido nas bibliografias e políticas públicas como sendo o parâmetro ideal para as áreas verdes. Ainda que esse indicador não tenha respaldo nos dados referentes ao aprimoramento ambiental, vale como um parâmetro tornando as cidades comparáveis entre si, no entanto, não é o melhor índice para apoiar políticas públicas locais.

Em são Paulo, o presente estudo demonstra como a escala espacial enviesa o cálculo do IAVT, analisando os indicadores de área verde do município de São Paulo em diferentes escalas geográficas, resultando em padrões diferentes de exposição da população à extensão das áreas verdes. Os resultados obtidos mostraram três realidades distintas: a primeira na análise do município em sua totalidade, a segunda por região (Zona Norte, Sul, Leste, Oeste e Centro) e a terceira por subprefeitura (32 no total).Na primeira, ao considerar-se o munícipio em sua totalidade, 
os valores resultantes, apresentados na Erro! Fonte de referência não encontrada., não apenas atendem aos parâmetros ideais atribuídos a OMS, como os superam com folga de pelo menos $40 \%$. No entanto, já no segundo cenário, analisando as regiões do munícipio, tem-se que apenas as Regiões Norte e Sul atendem aos indicadores propostos. Este resultado apresenta como o índice de vegetação está propenso a um viés relacionado à presença de grandes áreas florestadas. Contudo, as áreas florestadas não são as que possuem maior densidade demográfica na cidade, mostrando então que esse benefício atende a poucas pessoas. E, por fim, ao analisar o município por subprefeitura, sendo este o terceiro cenário proposto, verifica-se que apenas 10 das 32 subprefeituras atendem aos indicadores ideais, ou seja, apenas $30 \%$ das subprefeituras atendem aos parâmetros ideais atribuídos à OMS.

Os resultados sugerem que a distribuição das áreas verdes não está adequada em relação à densidade demográfica e a verticalização do município, e apontam para a desigualdade ambiental no município de São Paulo. Considerando que o IAVT tem como propósito a avaliação da distribuição das áreas verdes públicas na cidade, é muito difícil utilizar este índice numa região tão complexa como São Paulo, já que é modificado de forma notável de acordo com a escala espacial utilizada. Portanto, o IAVT não representa a realidade ambiental do município, vez que o indicador exclui a arborização urbana e não considera para o cálculo a parcela da ocupação das áreas, que podem ser mais urbanas. Diante do exposto, verifica-se que não tem como comparar a proporção de áreas verdes quando há áreas extensas de floresta natural. Nesse sentido, cabe uma sugestão para trabalhos futuros que é a inserção desse fator no cálculo do indicador IAVT.

Ainda, ao comparar-se os indicadores reais do munícipio de São Paulo com os parâmetros de outras cidades, como por exemplo, uma cidade metropolitana da Argentina, nota-se que os resultados são ainda piores do que os obtidos, visto que o indicador ideal passa de $12 \mathrm{~m}^{2}$ para $25 \mathrm{~m}^{2}$ de áreas verdes por habitante, fazendo com que, na análise do município em sua totalidade, resulte em valor cerca de $30 \%$ abaixo do ideal. Portanto, como uma segunda sugestão para o desenvolvimento de trabalhos futuros, é o estudo dos indicadores ideais para o munícipio de São Paulo, que considerem também a arborização urbana e pondere o nível de adensamento populacional na região.

A comparação dos índices calculados com os valores de 2017 e com a previsão para 2020 mostram ainda que, apesar das políticas públicas do município, o governo não está levando em consideração esses índices para as tomadas de decisão, fazendo com que não se diminuísse os desequilíbrios ambientais dentro da cidade, uma vez que se prevê a ampliação de áreas verdes em regiões bastantes abastadas desse tipo de equipamento. Destaca-se, entretanto, que a utilização desse indicador em análises locais pode ter impacto positivo na implementação de planos, programas e projetos e em iniciativas como o Programa de Metas, por garantir a diminuição da desigualdade ambiental no município.

Por fim, estes índices devem ser utilizados de forma consistente para elaboração de políticas públicas de desenvolvimento regional com foco na diminuição das desigualdades ambientais, e tem papel de destaque os resultados do IAVT por subprefeitura no município de São Paulo. Referido índice pode ser adotado como parâmetro de tomada de decisão para a ampliação das áreas verdes na cidade, tais como a implantação de parques, buscando a correção e equilíbrio na distribuição das áreas verdes na cidade.

\section{Agradecimentos}

Os autores agradecem à Secretaria do Verde e do Meio Ambiente pelo fornecimento dos dados utilizados neste estudo, e à Fundação de Amparo à Pesquisa do Estado de São Paulo (FAPESP 2019/08783-0, 2020/09251-0), à Coordenação de Aperfeiçoamento de Pessoal de Nível Superior pelo financiamento, o Conselho Nacional de Desenvolvimento Científico e Tecnológico - CNPq (Processo 311357/2016-4) pelo apoio ao desenvolvimento das pesquisas. 


\section{Referências}

ACSELRAD, H. Discursos da sustentabilidade urbana. Revista brasileira de estudos urbanos e regionais, 1999.

ALVES, H. P. D. F. Desigualdade ambiental no município de São Paulo: análise da exposição diferenciada de grupos sociais a situações de risco ambiental através do uso de metodologias de geoprocessamento. Revista Brasileira de Estudos de População, 2007, p. 301-316.

ASGARZADEH, M.; LUSK, A.; KOGA, T.; HIRATE, K.. Measuring oppressiveness of streetscapes. Landscape and Urban Planning, 2012, p. 1-11.

BENAYAS, J. M. R.; NEWTON, A. C.; DIAZ, A.; BULLOCK, J. M. Enhancement of biodiversity and ecosystems services by ecological restoration: a meta-analysis. Science, v.325, n.5944, 2009, p.11211124.

BRASIL. Constituição (1988). Constituição da República Federativa do Brasil. Brasília, DF: Senado Federal: Centro Gráfico, 1988, 292 p.

BUCKERIDGE, M. Árvores urbanas em São Paulo: planejamento, economia e água. Estudos Avançados, v.29, 2015, p.85-101.

BUCKERIDGE, M. Bases Históricas e Científicas da Ética Socioambiental. In: FLOTIT, L. F.; SAMPAIO, C.A.C.; PHILIPPI JR., A. Ética Socioambiental. s. 1.: s. n., 2019. p.152-60.

CAVALCANTE, L. R. ABRANGÊNCIA GEOGRÁFICA DAS POLÍTICAS DE DESENVOLVIMENTO REGIONAL NO BRASIL. Revista Brasileira de Gestão e Desenvolvimento Regional, v. 16, n. 2, 2020.

CARNIELLO, M. F.; DOS SANTOS, M. J.. Comunicação e desenvolvimento regional. Revista brasileira de gestão e desenvolvimento regional, v. 9, n. 2, 2013.

CARVALHO, G. O. Sustentabilidade e desenvolvimento sustentável: uma visão contemporânea. Revista Gestão \& Sustentabilidade Ambiental, 8(1), p. 789-792. Recuperado de DOI: 10.19177/rgsa.v8e12019779-792, 2014.

CORTESE, T. T. P.; NATALINI, G. Mudanças Climáticas (1a ed.). São Paulo: Manole, 2014.

CORTESE, T. T. P., KNIESS, C. T., \& MACCARI, E. A. Cidades inteligentes e sustentáveis. São Paulo: Manole, 2017.

Decreto n. 9.810 de 30 de maio de 2019. Dispõe sobre o Plano de Desenvolvimento Regional. Recuperado de http://www.planalto.gov.br/ccivil_03/_Ato2019-2022/2019/Decreto/D9810.htm

ELKINGTON, John. Partnerships from cannibals with forks: The triple bottom line of 21st-century business. Environmental quality management, v. 8, n. 1, 1998, p. 37-51.

FERREIRA, L. S.; DUARTE, D. H. S. Exploring the relationship between urban form, land surface temperature and vegetation indices in a subtropical megacity. Urban Climate, 27, 2019, p. 105-123.

FREITAS, L. C. Políticas de responsabilização: entre a falta de evidência e a ética. Cadernos de Pesquisa, v. 43, n. 148, p. 348-365, 2013.

FUNDAÇÃO SEADE. Índice Paulista de Vulnerabilidade Social. Disponível em: <http://www.seade.gov.br/ipvs/>. Acesso em: 10 out. 2019.

GEOSAMPA. Mapa Digital da Cidade de São Paulo. Disponível em: <http://geosampa.prefeitura.sp.gov.br/PaginasPublicas/_SBC.aspx>. Acesso em: 03 out. 2019. 
GU, D.; GERLAND, P.; PELLETIER, F.; COHEN, B. Risks of exposure and vulnerability to natural disasters at the city level: A global overview. New York: United Nations, Techinical Paper, 2015.

HARDER, I. C. F., RIBEIRO, R. D. C. S., \& TAVARES, A. R. (2006). Índices de área verde e cobertura vegetal para as praças do município de Vinhedo, SP. Revista Árvore, 30(2), 277-282.

HUFF, D. Como mentir com estatística. Rio de Janeiro: Intrínseca, 2016.

INSTITUTO BRASILEIRO DE GEOGRAFIA E ESTATÍSTICA. Dados de população estimada residente de São Paulo. Disponível em: < https://cidades.ibge.gov.br/brasil/sp/saopaulo/panorama >. Acesso em: 03 out. 2019.

JUSTI, A. P.; RAUEN, W. B., GESTÃO INTEGRADA DE RECURSOS HÍDRICOS E USO DO SOLO URBANO NAS PRINCIPAIS LEIS FEDERAIS BRASILEIRAS. Revista Brasileira de Gestão e Desenvolvimento Regional, v. 16, n. 2, 2020.

LEITE, C. e AWAD, J. di C. M. Cidades Sustentáveis, Cidades Inteligentes: Desenvolvimento sustentável num planeta urbano. Porto Alegre: Bookman, 2012.

LARSEN, T. A,; HOFFMANN, S.; LÜTHI, C.; TRUFFER, B.; MAURER, M. Emerging solutions to the water challenges of an urbanizing world. Science, v. 352, n. 6288, p. 928-933, 2016.

LOCOSSELLI, G.M.; MOREIRA, T. C. L.; CHACÓN-MADRID, K.; ARRUDA, M. A. Z.; CAMARGO, E. P.; KAMIGAUTI, L. Y.; TRINDADE, R. I. F.; ANDRADE, M. F.; ANDRÉ, C. D. S.; ANDRÉ, P. A.; SINGER, J. M.; SAIKI, M.; ZACARELLI-MARINO, M. A.; SALDIVA, P. H. N.; BUCKERIDGE, M. S. Spatial-temporal variability of metal pollution across and industrial district, evidencing the environmental inequality in São Paulo. Environmental Pollution, p. 114583, 2020.

MAILLAT, D. Innovative milieux and new generations of regional policies, Entrepreneurship \& Regional Development: An International Journal, v. 10, n. 1, p. 1-16, 1998.

MARENGO, J. A.; ALVES, L. M.; AMBRIZZI, T.; YOUNG, A.; BARRETO, N. J. C.; RAMOS, A. M. Trends in extreme rainfall and hydrogeometeorological disasters in the Metropolitan Area of São Paulo: a review. Annals of the New York Academy of Sciences, 2020.

MARÓSTICA, J. R. Sustentabilidade urbana e indicadores de área verde no município de São Paulo. Dissertação (Mestrado em Cidades Inteligentes e Sustentáveis) - Universidade Nove de Julho. São Paulo, p. 166, 2019.

MARTINS, G. D. A.; THEÓPHILO, C. R. (2009). Metodologia da investigação cientifica, São Paulo: Atlas.

MINISTÉRIO DE DESENVOLVIMENTO REGIONAL. Política Nacional de Desenvolvimento Regional - PNDR. Disponível em: https://www.mdr.gov.br/desenvolvimento-regional-eurbano/politica-nacional-de-desenvolvimento-

regional\#: : text =Pol\%C3\%ADtica\%20Nacional\%20de\%20Desenvolvimento\%20Regional,site\%20po dem\%20n\%C3\%A30\%20estar\%20acess\%C3\%ADveis. Acesso em: 27 jul. 2020.

MORAR, T.; RADOSLAV, R.; SPIRIDON, L. C.; \& PĂCURAR, L. Assessing pedestrian accessibility to green space using GIS. Transylvanian Review of Administrative Sciences, v. 10, n. 42, p. 116-139, 2014.

MOREIRA, T. C. L.; POLIZEL, J. L.; SANTOS, I.S.; FILHO, D. F. S.; BENSENOR, I.; LOTUFO, P. A.; MAUAD, T. Green spaces, land cover, street trees and hypertension in the Megacity of São Paulo. International Journal of Environmental Research and Public Health, v. 17, n. 3, p. 725, 2020.

MOREIRA, T.C.L, AMATO-LOURENÇO, L.F., DA SILVA G.T, ANDRÉ, C.D.S., ANDRÉ, P.A., BARROZO, L.V., SINGER, J.M., SALDIVA, P.H.N., SAIKI, M., LOCOSSELLI, G.M. (2018) The use 
of tree barks to monitor traffic related air pollution: a case of stady in São Paulo - Brazil. Frontiers in Environmental Science 6: 72.

MUIS, S.; GÜNERALP, B.; JONGMAN, B.; AERTS, J.C.; WARD, P. J. Flood risk and adaptation strategies under climate change and urban expansion: A probabilistic analysis using global data. Science of Total Environment v. 538, p. 445-457, 2015.

PREFEITURA MUNICIPAL DE SÃO PAULO. Programa de Metas 2017-2020. Disponível em: $<$ http://programademetas.prefeitura.sp.gov.br/assets/up/Programa\%20Metas\%2020192020 texto.pdf $>$. Acesso 20 abr. 2019.

SALDIVA, P. Vida urbana e saúde: os desafios dos habitantes das metrópoles. São Paulo: Editora Contexto, 2018.

SHASHUA-BAR, L.; HOFFMAN, M. E. Vegetation as a climatic component in the design of an urban street: An empirical model for predicting the cooling effect of urban green areas with trees. Energy and buildings, v. 31, n. 3, p. 221-235, 2000.

SILVA, E. M. F.; BENDER, F.; MONACO, M. L. S.; SMITH, A. K.; SILVA, P.; BUCKERIDGE, M. S.; ELBL P. M., LOCOSSELLI, G. M. Um novo ecossistema: florestas urbanas construídas pelo Estado e pelos ativistas. Estudos Avançados, São Paulo, v. 33, n. 97, p. 81-102, dez. 2019.

SECRETARIA DO VERDE E DO MEIO AMBIENTE. Parques Implantados em 2018, 2019 e Planejamento para 2020. Disponível em: $<$ https://www.prefeitura.sp.gov.br/cidade/secretarias/controladoria geral/coordenadoria de prom ocao_da_integridade/index.php?p=225079> . Acesso em: 21 set. 2019.

SECRETARIA DO VERDE E DO MEIO AMBIENTE. Dados de Área Verde por Subprefeitura. Disponível em: $<$ https://www.prefeitura.sp.gov.br/cidade/secretarias/controladoria geral/coordenadoria de prom ocao da integridade/index.php? $\mathrm{p}=225079$ > . Acesso em: 21 set. 2019.

SECRETARIA DO VERDE E DO MEIO AMBIENTE. Parques Implantados em 2018, 2019 e Planejamento para 2020. Portal da Transparência, 2019.

SECRETARIA DO VERDE E DO MEIO AMBIENTE. Áreas Verdes. Disponível em: $<$ http://www.prefeitura.sp.gov.br/cidade/secretarias/upload/planejamento/Verde\%2010_2013.xls. $\underline{20 / 04 / 2019>\text {. }}$

SINDICATO DAS EMPRESAS DE COMPRA VENDA, LOCAÇÃO E ADMINISTRAÇÃO DE IMÓVEIS RESIDENCIAIS E COMERCIAIS DE SÃO PAULO - SECOVI. Valores de imóvel por $\mathrm{m}^{2}$. 2019. Disponível em: https://secovi.com.br/pesquisas-e-indices\#indicadores de mercado. Acesso em: 21 set. 2019.

SOCIEDADE BRASILEIRA DE ARBORIZAÇÃO URBANA - SBAU. "Carta a Londrina e Ibiporã". Boletim Informativo, v.3 , n.5, p.3, 1996.

SOTTO, Debora et al . Sustentabilidade urbana: dimensões conceituais e instrumentos legais de implementação. Estud. av., São Paulo , v. 33, n. 97, p. 61-80, Dec. 2019 . Disponível em $<$ http://www.scielo.br/scielo.php?script $=$ sci_arttext\&pid $=$ S0103-

40142019000400061\&lng $=$ en\&nrm=iso $>$. Acesso em 20 Ago. 2020. Epub Dec 02, 2019. https://doi.org/10.1590/s0103-4014.2019.3397.004.

THE NATURE CONSERVANCY. Funding Trees for Health. An Analysis of Finance and Policy Actions to Enable Tree Planting for Public Health, 2019.

TORRES, H. D. G.; MARQUES, E.; FERREIRA, M. P.; BITAR, S. Pobreza e espaço: padrões de segregação em São Paulo. Estudos avançados, v. 17, n. 47, p. 97-128, 2003. 
Esta obra está licenciada com uma Licença Creative Commons Atribuição 4.0 Internacional. 